\title{
Toward A Concept Of Territorial Retailing Strategy
}

Dr. E. K. Valentin, Marketing, Weber State College

\begin{abstract}
Conventional geographic retail market selection criteria are potentially misleading and speciously isolated from interrelated strategic decisions. In fact, current concepts of territorial retailing strategy are superficial at best. The framework developed in this article provides a start toward mitigating the noted shortcomings.
\end{abstract}

\section{Introduction}

Few, if any, commitments have a greater impact on a retailer's fortunes than physical expansion decisions. Yet, criteria for choosing towns, cities, MSAs, or ADIs--local markets in which to compete--remain primitive and isolated from other facets of retailing strategy. Moreover, to date, the concept of territorial strategy is but a vague notion (Mason and Mayer 1987). A richer and a more efficacious portrayal of the territorial expansion problem, including market selection, is developed in this article. The discussions apply directly to chains and indirectly to single-store retailers concerned about threats posed by larger rivals.

\section{Explication of the Problem}

At the first glance, any of the multi-site selection models developed throughout this decade may seem useful in identifying attractive local markets (Achabal, Gorr, and Mahajan 1982; Craig, Ghosh, and McLafferty 1984; Ghosh and Craig 1983). However, as their inventors generally admit, such models were intended mainly to facilitate finding the optimum number and the ideal spatial distribution of stores to be operated within a preselected area. True market evaluation models reported in the literature or used by practitioners usually rely on estimates of saturation--that is, estimates of local sales potential per unit of capacity. The larger the ratio, the more attractive the market (LaLonde 1961; Lilien and Kotler 1983, pp. 447-449).

But results from several studies imply attrac- tiveness is contingent on the match between market and retailer attributes; hence, conventional measures may mislead (Hirschman 1978; Ingene 1984). Ingene and Lusch (1980), for instance, found mean department store expenditures per household across 213 SMSAs for the year 1972 ranged from $\$ 232$ to $\$ 1,448$. They discovered equally dramatic variations within other broad retailing categories and, hence, cautioned retailers against relying on saturation indices. Also, Arnold, Oum, and Tigert (1983) revealed food shoppers in St. Louis, where warehouse and box formats are prevalent, were less attracted by convenience than consumers in other test cities; and food shoppers in Tampa were very sensitive to assortment, but relatively insensitive to price. Moreover, several prominent chains, reportedly, have realized conventional criteria diverted them from rural markets where numerous less sophisticated "upstarts," such as Wal-Mart, have made fortunes (Miller 1986).

From these and other studies and reports it seems evident an attractive local market is more than a collection of desirable sites or one characterized by a low level of intratype competition. An attractive market is one wherein the firm's weakness are inconsequential and its strengths can be used to gain economically significant competitive advantages (SCAs).

Understanding the sources of SCAs is the key to intelligent strategic decision making, which is especially critical during the growth stage of a retailing form's life cycle and when new forms 
of intertype competition emerge (Porter 1980, 1985). It is then, while the competitive environment is in flux, that much of the groundwork for eventual success or failure is laid (Abell 1978; Howard 1983). Accordingly, Figure 1 is intended to illuminate local market alternatives by depicting them within the context of broader territorial alternatives and the overall geographic expansion problem.

In essence, the figure suggests the viability of a retailing venture is determined by territorial choices, various internal parameters, and dynamic external environments. SCAs and expected longterm profitability are the criteria used to evaluate territorial choices, which are comprised of three decision variables: type of market, geographic scope, and market penetration. Later, distinctions among local markets are drawn in terms of demand attributes (size, heterogeneity, and growth rate) and their impact on the competitive environment. Geographic scope refers to the spatial breadth of a retailer's activities (e.g., local, regional, or global); and market penetration is synonymous with local market share.

The internal parameters--decision variables held constant for the particular purposes of an analysisconsist of resource constraints and the selected retailing format. Typically, the principal resource

FIGURE 1

\section{A Systems Perspective of Territorial strategy}

Internal Parameters

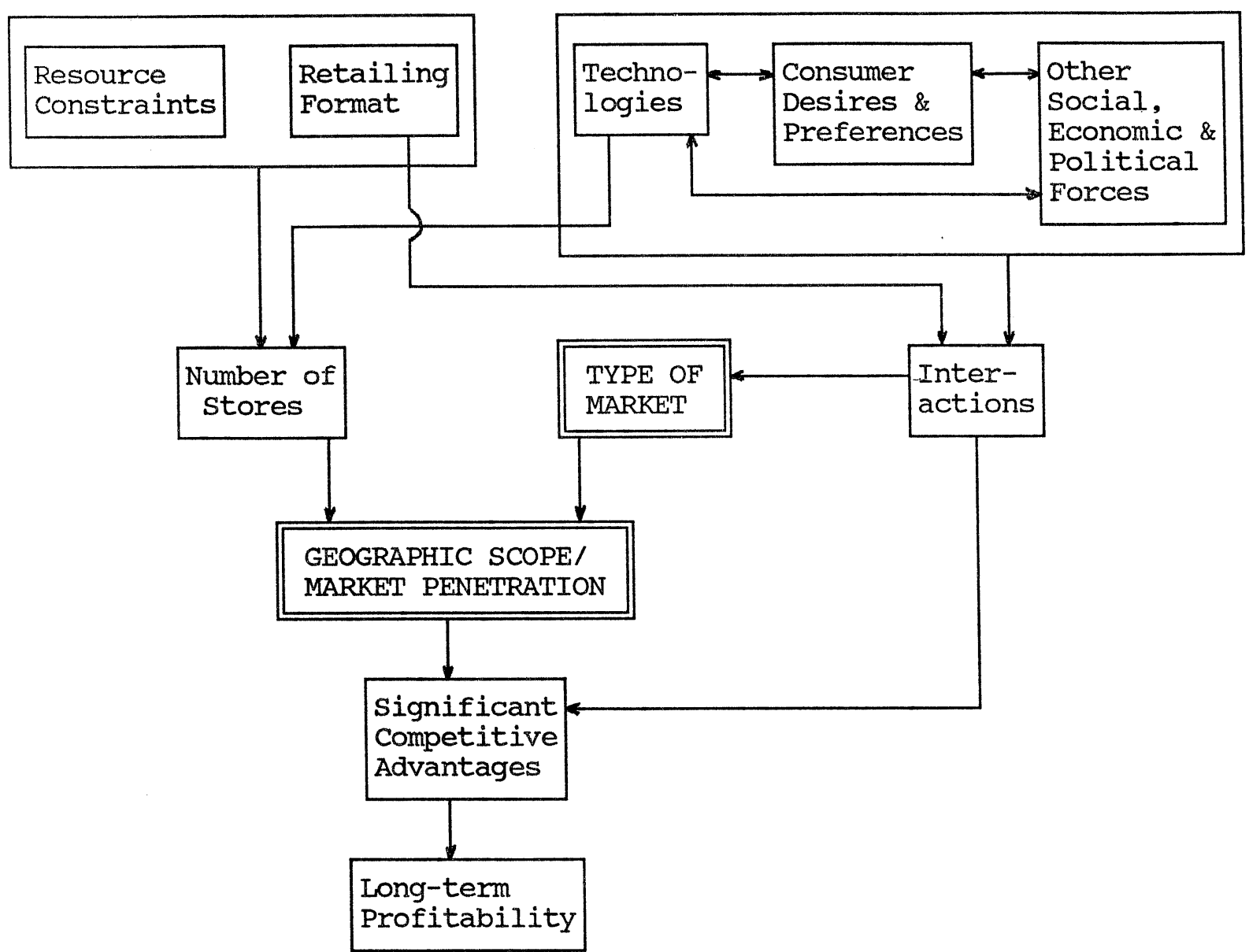


The Journal of Applied Business Research - Vol. 6, No. 1

constraints are money and experienced people (Higgins and Kerin 1983). The retailing format is defined primarily by the lines of merchandise carried and secondarily by firm-specific variations. For example, at the primary level, the shoe store format differs from that of the department store; and at the secondary level, Mervyn's format differs from J.C. Penney's.

Technologies, consumer desires and preferences, and other social, economic, and political forces comprise the external environmental variables (Achrol, Reve, and Stern 1983). The retailer's control over such variables is assumed to be negligible; therefore, an adaptive stance is required. But, external environments are apt to change over the course of the life cycle. Also, whether and how extant technologies are applied is a matter of managerial choice and resource constraints. Prices and consumer desires and preferences jointly determine the demand for particular service outputs--core goods and services, such as groceries and haircuts, and enhancements, such as convenience, assortments, atmospherics, and information.

The market selection problem depicted in Figure 1, then, parallels the conventional specification insofar as it is assumed (1) the retailing format has been selected and, hence, is not an issue; (2) resources are limited; and (3) external environments are uncontrollable. It differs from the conventional specification insofar as (1) the objective is to identify an attractive type of local market, rather than a particular understored city, county, MSA, or ADI; and (2) three decision variables--market type, geographic scope, and market penetration--are to be evaluated jointly with respect to long-term profitability. The central tenet can be summarized as follows:

* Resource constraints, the chosen format, and available technologies limit the number of stores that can be operated and, hence, the geographic coverage and market penetration attainable.

* SCAs and profitability are partly determined by interactions among the local demand and supply characteristics of a market, retailing format, technologies, consumer desires and preferences, and other external environmental forces.

* SCAs and profitability also are affected directly by the strategic decision variables (geogra- phic scope, local market penetration, and market type).

Below, links between performance and geographic scope, as well as links between performance and local market penetration, are examined first. Then, interactions among scope, penetration, and local market characteristics are sorted out, and their effects on competitive structure are noted.

\section{Scope, Penetration, and SCAs}

Geographic scope refers to territorial participation, which may be local, regional, or global (i.e., multi-regional). Penetration can be characterized via three market share positions: minority, coequal, and dominant. Which and how many scope/penetration combinations will be viable in the long run depends largely on whether geographic scope or market penetration affect the retailer's effectiveness or cost structure.

The impact of scope/penetration decisions on effectiveness and efficiency is understood most readily by viewing extant and alternative retailing formats and configurations as competing systems. A retailing microsystem is comprised of the store and all subsystems, such as departments; a retailing macrosystem encompasses configurations serving local, regional, and more extensive geographic markets. Issues addressed in this article are limited to the macro levels.

\section{Effectiveness, Efficiency, and Evolution}

A retailing firm is effective to the extent that its service outputs are preferred by a potentially profitable market segment; it is efficient to the extent that rivals cannot provide equivalent service outputs at lower cost. Efficiency without effectiveness is worthless.

Firms may use cost advantages to increase market share by attracting customers with lower prices, promotions, and service output enhancements that less efficient competitors cannot offer without raising prices. Whether a firm operates effectively or efficiently depends largely on its utilization of technologies. On a grand scale, technologies include retailing formats and entire systems whereby chains serve customers.

Retailing systems are hierarchical insofar as 
firms may evolve from local into regional or even global enterprises. Regional and global configurations usually are synergetic rather than mere agglomerations of independent subsystems; hence, scope decisions frequently affect profitability. To be exact, regional and global retailers may benefit from expert advertising, merchandising, and purchasing staffs that are uneconomical at the local level. Wal-Mart, for example, attributes much of its spectacular success to its network of distribution centers (Marketing News, June 20, 1986, p. 18).

Ineffective and inefficient retailers eventually will fail. Moreover, theoretically, channels serving any market will evolve until no improvement is possible (Bucklin 1972; Stern and El-Ansary 1988, p. 19).

\section{Scale as a Source of SCAs}

From nothing more than casual observation, it is evident that, in some lines of retailing, smallscale enterprises can compete tenaciously. On the other hand, it also is apparent many small retailers have been displaced by chains. Hence, the question arises: To what extent are SCAs rooted in scale? Scale is a correlate of sales volume; hence, scale effects comprise economies and diseconomies that arise as sales volume increases.

Scale effects may enhance or diminish effectiveness or efficiency (Carman and Langeard 1980). As an illustration, consider the cost of developing a tabloid. The average development cost per store declines as the number of stores covered increases. However, the effectiveness of a multi-market tabloid is impaired to the extent that customer desires and preferences differ from one market to another. Also, coordination problems are likely to arise as the number of outlets involved increases.

The strategic significance of gaining a coequal or greater market share at any geographic level depends on three interrelated factors: (1) the impact of scale effects, (2) the transferability of technology, and (3) risk and convenience (Carman and Langeard 1980; Lilien and Rao 1976; Kelly and George 1982; Schmenner 1986).

Impact of scale effects. When running commercials on local television, for example, the cost of air time can be spread over all (local) stores covered. Moreover, if the same ad can be used in all markets, development cost can be spread over all stores in the system. As a chain grows, it becomes increasingly feasible to hire functional specialists who can increase the retailer's effectiveness.

Technology transfer. Technologies are transferable if processes or process outputs can be used in several places. Using the same advertisement in several markets is one example. Additional examples include planograms, store layouts, and site selection models, which may or may not be produced internally. Frequently, it is not feasible to acquire particular technologies or the capability to develop them unless they can be applied widely.

Risk and convenience. McDonald's golden arches, for example, are widely recognized and associated with a particular offering that varies little among outlets. Hence, customers who have enjoyed a meal at one McDonald's restaurant do no hesitate to visit another because risk and learning demands are minimal. Similarly, Sears, Marshall Fields, and others have relied on convenience and reputations developed as sellers of merchandise to gain footholds in various types of service retailing (Kelly and George 1982).

In summary, size, especially in relation to competitors, often is a source of SCAs. However, scale effects, favorable and unfavorable, may be operative at one or more territorial levels. Moreover, the type of local market may determine whether local scale effects are critical. For example, some markets may support no more than a single establishment of a particular kind; hence, from a macrosystem perspective, no local scale effects are operative. Yet, regional or global effects may be substantial. In some contexts, size is important irrespective of geographic scope. For instance, the success of the Limited's efforts to secure SCAs via backward integration into manufacturing is more sensitive to the total number of stores operated than to penetration at any territorial level.

\section{Differentiation as a Source of SCAs}

Effectiveness requires matching service outputs to consumer desires and preferences. Differences in buyer evaluations of service outputs 
and output combinations--i.e., demand heterogeneity--and technology determine whether a retailer's profitability can be enhanced by differentiating service outputs (Stern and El-Ansary 1988).

Differentiation may be nothing more than the result of muddled efforts to develop a quality product or service that stands out from the rest (e.g., the best hamburger in town). It may be neither carefully planned nor aimed at any welldefined segment. For instance, some degree of spatial differentiation among sores is inadvertent. Also, highly service-oriented offerings tend to be differentiated because they are inseparable from the individuals who provide them (Kelly and George 1982).

Sometimes, differentiation results from the retailer's incremental efforts to adapt to apparent customer preferences. Or, it may be known at the outset that customization is required to meet individual expectations (Schmenner 1986). Hence, establishments may differentiate themselves according to how extensively and how well they customize. When effective customization is the critical success factor, it seems more difficult to utilize size to create a positive net impact because efforts to guarantee consistent quality usually entail standardization, and standardization reduces flexibility and effectiveness (Berry 1986). Consequently, barbers, mechanics, insurance agents, and the like, frequently develop clienteles more loyal to them, personally, than to the firms with which they are affiliated. Nevertheless, few, if any, such services are entirely beyond the purview of scale effects and the mass merchant (Kelly and George 1982).

Although differentiation tends to reduce price sensitivity, it seldom leaves much room for inefficiency. After all, even consumers who demand top-quality merchandise frequently compare prices and usually are willing to pay only a small premium for amenities. Moreover, whenever a cheaper way of producing a particular bundle of service outputs exists, sooner or later, someone will use it. Therefore, as long as scale effects remain significant and favorable, differentiation affords small retailers only a thin margin of protection against larger, more efficient rivals. The pervasiveness of specialty chains confirms that differentiated, focused large-scale retailing can be efficient as well as effective. The small retailer's survival, then, depends on SCAs not rooted in scale effects.

\section{SCAs not Attributable to Scale}

To speculate perceptively about future competitive environments, all sources of SCAs--not only those linked to scale--must be understood. Customer loyalty may be one such source. It has been noted, for instance, that rural customers tend to be extremely loyal; therefore, the first store of its type in town has a definite advantage (Miller 1986). Proprietary technologies, also, may provide SCAs. For a time, proprietary inventory control software gave some retailers an edge. Moreover, small entrenched retailers may have much lower occupancy costs than newcomers because they acquired their facilities when land and building costs were comparatively low; or they may hold favorable long-term leases.

\section{Scope/Penetration/Market-Type Interactions}

In this section, the effects of local demand attributes on the competitive environment are summarized first; then, the viability of several prevalent territorial objectives is assessed in view of the retailer's format, resource constraints, and local market characteristics.

\section{Local Demand and Competition}

Market size, demand heterogeneity, and market growth are the main determinants of local competitive structures.

Market size. In comparatively large markets, (1) sales potential is high; (2) multiple outlets, intensive segmentation, and focused formats are more feasible (Forbes 1972); (3) economies of scale are likely sources of SCAs; (4) preemption, i.e., territorial monopolization, is more difficult (Eaton and Lipsey 1979; West 1981); (5) more outshoppers will be drawn from adjacent communities than will be lost; and (6) customers tend to be less loyal to particular establishments than in small markets (Berry, Barnum and Tennant 1962; Miller 1986; Papadopoulos 1980).

Demand heterogeneity. At the local level, as at any other, diversity among customer desires and preferences, in conjunction with segment size and technology, affects the extent to which segmentation is feasible and the levels of intra- 
and intertype competition (Rosenbloom 1976). Moreover, a retailer's ability to enter or defend a market depends significantly on interactions between a firm's relative competencies and the sort of heterogeneity that characterizes a market-e.g., many small segments exhibiting weak differential preferences or a few large segments exhibiting strong differential preferences. In the latter case, focused specialty retailers may gain customers at the expense of mass merchandisers (Forbes 1972).

Market growth rate. Rapidly growing markets afford the prospect of extraordinary returns, but tend to be highly contested, especially when they are large. To establish or retain their positions, retailers may be forced to fight for market share by adding unprofitable capacity, providing unprofitable services, or engaging in promotional battles. Firms that might have done well in less competitive arenas may find it impossible to recover. Also, as local markets grow, the efficacy of focused retailing increases while that of mass merchandising decreases; hence, market shares may shift among formats (Forbes 1972).

\section{Market Strategies}

The most prevalent territorial objectives are (1) dominate locally, regionally, or globally; (2) skim; (3) stake out; or (4) defend a niche. The issue addressed at this juncture is the viability of each objective with respect to market types differing in terms of size, heterogeneity, and growth. To the extent SCAs derive from size, retailers are compelled to grow until they reach a competitive configuration.

Dominate locally, regionally, or globally. When favorable local scale effects are substantial, gaining a dominant share of each targeted local market is the most obvious route to profitability (Porter 1985). Local dominance is most easily achieved in small markets (Miller 1986). Wal-Mart (discount department stores) and Lowes (home improvement) are two prominent chains that became very successful by dominating rural markets. Resources that may be less than sufficient to secure a niche in a large market, may be adequate to dominate a small one. Hence, innumerable small chains and even singlestore retailers still manage to preempt markets. Nevertheless, when small markets are growing rapidly or when service is ineffective or ineffi- cient, rivals may challenge entrenched establishments, even though no immediate payoff is expected (West 1981).

Large markets are much less amenable to domination, as the presence of several, roughly, coequal grocery and department store chains within every major city implies. Even grocery shoppers seem to demand some variety; hence, an interesting alternative to the dominant format, though it may be inefficient and its offering may be high-priced, is apt to attract enough customers to make it viable when adding another store of the dominant type would only cannibalize sales from existing dominant units (Stern 1986).

When virtually all scale effects are operative at the local market level, dominant local retailers have little to fear from large chains. If regional or global scale effects are substantial and favorable, then survival in the long run is likely to require participation at those levels. Hence, growth may be an imperative, not an option.

Skim. During the growth stage of a retailing form's life cycle, the "better mousetrap" strategy often does work. That is, due to novelty and lack of competition, new formats frequently generate high sales volume and high profits with very little marketing effort. Rather than competing against itself by opening more stores within a local market, a chain encountering such ideal circumstances may conclude it is more profitable to build outlets in markets not yet served. But such skimming fails to discourage competitors. For example, Boise Cascade's Building Materials Distribution Division, which is now defunct, but once operated more than 100 home centers, found skimming profitable, albeit only for a short time. As the chain grew, no attempts were made to preempt markets (West 1981). Rivals found Boise Cascade easy prey, especially in metropolitan markets.

Stakeout. When staking out a market, the idea is to see how well a single store performs in an unfamiliar locale before making further commitments and to put rivals on notice. For example, Payless Cashways, a very successful home improvement retailer, implemented a stakeout strategy in the 1970 s, but shifted to entrenchment in the early 1980s. Nevertheless, Payless Cashways discovered that, if too many 
markets are staked out and rivals threaten several such markets at once, the resources needed to entrench quickly may not be at hand (Valentin 1988).

Defend a local niche. A local niche is characterized by a low local market share and a notably differentiated offering. It is most readily defended when favorable scale effects are negligible and demand for the unique offering is strong. Standardization and rigid corporate policies frequently encumber chains, thus, providing opportunities for smaller rivals, especially when a personal touch means a lot (Berry 1986; Tigert, Ring, and McCammon 1988). Yet, chains continue to find ways of using size to advantage, even in service oriented retailing (Kelly and George 1982).

\section{Retailing Dynamics and Territorial Alterna- tives}

Retailing environments are dynamic: populations grow or shrink, age and income distributions shift, new forms of retailing emerge from time to time, and technological innovations alter the balance of power among competitors. Moreover, consumer desires and preferences change. No more than a few years ago, naive prognosticators argued that, when buying stereo systems, cameras, and personal computers, consumers would strongly favor retailers capable of providing competent technical advice (Hiller 1983). Yet today, many technologically sophisticated products are sold by discounters, warehouse stores, and even mail-order houses because many buyers no longer require technical assistance (Howard 1983). Here, it can be noted only that consumer preferences and technological advancements may change the levels at which scale effects are most substantial and that strategists should consider the potential impact of plausible changes in demand and technology on the efficacy of scope, penetration, and market-type decisions (Hiller 1986; Mason and Mayer 1987; Miller 1986; Rosenfeld 1985; Sheth 1983; Stern 1986; Zeithaml 1985).

Strategists also are well-advised to trace the evolution of retailing sectors further along on the life cycle path. From such analyses insights may be gained into imminent changes in the competitive structure of the focal sector. For example, the home improvement and the grocery sectors seem to be on the same track, but the grocery sector is a few years ahead. Hence, home improvement chains may gain insights into opportunities and impending threats by studying the evolution of grocery retailing.

\section{Summary and Concluding Comments}

Research results suggest conventional (geographic) market selection criteria are primitive, potentially misleading, and artificially isolated from interrelated strategic choices. Market type, geographic scope, and market penetration, it seems, affect a retailer's absolute and comparative effectiveness and efficiency jointly; hence, all three decision variables should be considered interactively rather than independently.

Many facets of the rather complex rationale for evaluating territorial alternatives delineated in this article were supported by previous studies. Nevertheless, the numerous conjectures comprise a rich source of empirical hypotheses. This article also implied the kinds of reasoning in which practitioners ought to engage and the kinds of hypotheses they should investigate with respect to their particular sectors so as to understand the nature of territorial strategy and attendant opportunities and threats clearly.

\section{References}

Abell, Derek F. (1978), "Strategic Windows," Journal of Marketing, 42 (July), 21-26.

Achabal, Dale D., W. Gorr and V. Mahajan (1982), "MULTILOC: A Multiple Store Location Decision Model," Journal of Retailing, 58 (Summer) 5-25.

Achrol, R. S., T. Reve and L. W. Stern (1983), "The Environment of Marketing Channel Dyads: A Framework for Comparative Analysis," Journal of Marketing, 47 (Fall), 55-67.

Amold, S. J., T. Oum and D. Tigert (1983), "Determinant Attributes in Retail Patronage: Seasonal, Temporal, Regional, and International Comparisons," Journal of Marketing Research 20 (May) 149-157.

Berry, B. J., H. G. Barnum and R. J. Tennant (1962), "Retail Location and Consumer Behavior," Papers and Proceedings of the Regional Science Association, 9, 65-106.

Berry, Leonard (1986), "Big Ideas in Services Marketing," Journal of Consumer Marketing 2 (Spring) 47-51.

Bucklin, Louis P. (1972), Competition and Evolution in the Distributive Trades, Englewood Cliffs, NJ: Prentice-Hall.

Carman James M., and Eric Langeard (1980), "Growth Strategies for Service Firms," Strategic Management Journal, 1 (JanuaryMarch), 7-22. 
Craig, Samuel C., A. Ghosh and S. McLafferty (1984), "Models of the Retail Location Process: A Review," Journal of Retailing, 60 (Spring) 5-36.

Eaton, B. C., and R. G. Lipsey (1979), "The Theory of Market Pre-emption: The Persistence of Excess Capacity and Monopoly in Growing Spatial Markets," Economica, 46 (May) 149-158.

Forbes, J. D. (1972), "Central Place Theory -- An Analytical Framework for Retail Structure," Land Economics, 48 (February) 15-22.

Ghosh A., and C. S. Craig (1983), "Formulating Retail Location Strategy in a Changing Environment," Journal of Marketing, 47 (Summer) 56-68.

Higgins, R. C. and R. A. Kerin (1983), "Managing the Growth-Financial Policy Nexus in Retailing," Journal of Retailing, 59 (Fall), 19-48.

Hiller, Terry R. (1983), "Going Shopping in the 1990s: Retailing Enters the Future," The Futurist, (December) 63-68.

Hirschman, Elizabeth C. (1978), "A Descriptive Theory of Retail Market Structure," Journal of Retailing 54 (Winter) 29-48.

Howard, John A.(1983), "Marketing Theory of the Firm," Journal of Marketing, 47 (Fall), 90-100.

Ingene, Charles A. (1984), "Structural Determinants of Market Potential," Journal of Retailing, 60 (Spring) 37-64. and R. F. Lusch (1980), "Market Selection Decisions for Department Stores," Journal of Retailing 56 (Fall) 21-40.

Kelly, Patrick J., and William R. George (1982), "Strategic Management Issues for the Retailing of Services," Journal of Retailing, 58 (Summer) 26-43.

LaLonde, Bernard (1961), "The Logistics of Retail Location," American Marketing Association, Proceedings, 567-575.

Lilien, Gary L. and P. Kotler (1983), Marketing Decision Making: A Model-Building Approach, New York: Harper \& Row. and A. G. Rao (1976), "A Model for Allocating Retail Outlet Building Resources Across Market Areas," Operations

Research, 24 (January-February) 1-14.

Marketing News, 20 (June 20) 18.

Mason, J. Barry, and Morris L. Mayer (1987), Modern Retailing: Theory and Practice, Plano, TX: Business Publications.

Miller, Norman M. (1986), "Rural Retailing: The Last Frontier," Chain Store Age Executive, (March) 18, 19, 22.

Papadopoulos, N. G. (1980), "Consumer Outshopping Research: Review and Extensions," Journal of Retailing, 56 (Winter) 41-58.

Porter, Michael (1980), Competitive Strategy, New York: The Free Press. (1985), Competitive Advantage, New York: Free Press.

Rosenbloom, Bert (1976), "The Trade Area Mix and Retailing Mix: A Retail Strategy Matrix," Journal of Marketing, 40 (October) 58-66.

Rosenfeld, Judith (1985), "Revolutionizing Retail," Marketing Communications, (February) 66-70.

Schmenner, Roger W. (1986), "How Can Service Businesses Survive and Prosper?" Sloan Management Review, 27 (Spring) 21 32.

Stern, Aimee L. (1986), "Retailers Restructure," Dun's Business Month, (February) 28-32.

Stern, L. W. and A. El-Ansary (1988), Marketing Channels, Englewood Cliffs, NJ: Prentice-Hall.

Tigert, D. J., L. J. Ring and B. McCammon (1988), "Change the Strategy, Change the Management System: Do the Department Stores Dare Risk Success?" Journal of Services Marketing, 2 (Spring) 5-18.

Valentin, E. K. (1988), "Payless Cashways Inc.: 1981-1985," in Cases in Strategic Management, J. A. Pearce and R. B. Robinson, Eds., Homewood, IL: Irwin, 357-371.

West, D. S. (1981), "Testing for Preemption Using Sequential Location Data," Bell Journal of Economics, 12 (Spring) 129-143. Zeithaml, Valerie A. (1985), "The New Demographics and Market Fragmentation," Journal of Marketing, 49 (Summer) 64-75. 